\title{
Feeding niche segregation among the Northeast Atlantic community of oceanic top predators
}

\author{
C. Pusineri ${ }^{1}$, O. Chancollon ${ }^{1}$, J. Ringelstein ${ }^{1}$, V. Ridoux ${ }^{1,2, *}$ \\ ${ }^{1}$ LIENSs (LIttoral, ENvironnement et Sociétés), UMR 6250, and ${ }^{2}$ Centre de Recherche sur les Mammifères Marins, \\ Université de La Rochelle, 17071 La Rochelle cedex, France
}

\begin{abstract}
In the Northeast Atlantic, off the Bay of Biscay, the pelagic top predator community is mainly composed of the blue shark Prionace glauca, the swordfish Xiphias gladius, the albacore tuna Thunnus alalunga, the common dolphin Delphinus delphis and the striped dolphin Stenella coerulaeoalba. The present study is aimed at determining the patterns of feeding niche segregation among this oceanic top predator assemblage. Overlaps were measured in terms of prey taxa and prey sizes. Preferred foraging depth ranges and diel patterns were inferred from prey compositions and digestion conditions. In terms of prey taxa, the blue shark, the albacore and the swordfish segregated fairly well from each other and from the 2 dolphins, whereas the 2 dolphins showed considerable overlap. In terms of prey sizes, substantial overlap was found between the blue shark and the swordfish, but these predators differed from the 2 dolphins and the albacore, which, in turn, overlapped considerably. Spatio-temporally, the blue shark and the swordfish appeared to be predominantly diurnal mesopelagic predators, while the albacore and the dolphins were mostly nocturnal epipelagic feeders. Prey diversity was higher in the 2 dolphins, which also showed a lower interindividual variability in stomach content composition. The 2 dolphins have the highest energy needs and are bound to the surface for breathing; the albacore is also bound to the surface layer for physiological reasons (swim bladder development and body temperature control): all 3 rely on small gregarious epi- to vertically migrating mesopelagic prey species of high energy content. The swordfish and the blue shark have much lower energy needs and are not restricted to the surface layer; they are better able to forage on scattered, deep-living, large-size and low-energy prey. Hence, within the whole community, the energetics of predation and constraints relative to the sea surface are the main structuring factors, and not the relationship between predator size and prey size.
\end{abstract}

KEY WORDS: Top predator community $\cdot$ Diet $\cdot$ Oceanic Bay of Biscay $\cdot$ Foraging niche segregation

\section{INTRODUCTION}

Many studies have shown that the management of exploited species should be done at the ecosystem level, both to improve exploitation sustainability and to preserve the other resources (Garcia et al. 2003, FAO 2004); as a consequence, interest in fish community studies has grown, in addition to fishery management approaches. The understanding of community structures and functioning includes the identification of the ecological niche of each species and the assessment of the amount of niche overlap versus segregation between species (Pianka 1974, Ross 1986). This information allows one to identify the dimension(s) of the niche along which interspecific interactions might occur, and are then the first step to a better understanding of the ecosystems.

Ecological niche refers here to the biotic and abiotic conditions in which a species is living, the resources it consumes and the way it exploits them (Hutchinson 1957, Pianka 1978). The feeding niche is a subset of the ecological niche and is generally subdivided into 3 major dimensions: the trophic dimension (e.g. diet composition by prey taxa and prey length: Hopkins et al. 1996, Croxall et al. 1997, Bulman et al. 2002), the spatial dimension (e.g. feeding area and feeding depth: Diamond 1983, Potier et al. 2004) and the temporal dimension (e.g. diurnal feeding period: Harrison 
et al. 1983, Cabral et al. 2002). In studies of top predator feeding niches, the behavioural dimension is sometimes also considered (e.g. foraging techniques or tactics: Harrison et al. 1983, Ridoux 1994). Of course, these dimensions are not independent from one another (Pianka 1974). For example, trophic segregation within a community is often partly the expression of differences in feeding tactics and habitats (e.g. Ridoux 1994, Franeker et al. 2001).

Ross (1986), reviewing the literature on resource partitioning in fish assemblages, pointed out that trophic separation appeared to be more important than habitat and temporal separation. Furthermore, in aquatic ecosystems, trophic relations are believed to be largely determined by the size of the prey relative to the size of the predator (Cury et al. 2001). For example, body size was found to be an excellent predictor of trophic levels in the Northeast Atlantic fish community (Jennings et al. 2001). Similarly, mouth gaps in 18 species of Mediterranean fish were significantly related to body length and trophic levels (Karpouzi \& Stergiou 2003). Also, the vulnerability of a prey relates to body size in a dome-shaped function for any particular predator body size, and the position of the peak increases with predator size (Lundvall et al. 1999). Hence, feeding niche segregation in fish communities would mostly operate along the trophic dimension of the niche because of the strong relationship linking predator and prey sizes. However, this does not seem to be the rule in top predator communities. For example, in the Galapagos, fur seals Arctocephalus galapagoensis feed exclusively at night on loosely schooling, slow-swimming small prey species, while sea lions Zalophus californianus wollebeaki feed during the day on densely schooling, fast-swimming larger prey, which suggests important trophic, but also temporal and behavioural segregation (Dellinger \& Trillmich 1999). Similarly, in teuthophagous mesopelagic marine mammals, differences in niche breadth would be closely related to spatial (horizontal and vertical) segregation (Whitehead et al. 2003). Bigeye and yellowfin tunas in the tropical Indian Ocean segregate in the trophic dimension as a result of difference in feeding depths (Potier et al. 2004). Hence, in top predator communities, feeding niche segregation would operate along several dimensions of the feeding niche.

In the Northeast Atlantic, off the Bay of Biscay, the community of large pelagic top predators is mainly composed of the blue shark Prionace glauca, the swordfish Xiphias gladius, the albacore tuna Thunnus alalunga, the common dolphin Delphinus delphis and the striped dolphin Stenella coerulaeoalba. Other sharks, large fish and delphinids can be found in the area, but were not included in the analyses as they were sampled too rarely. The species-specific diet compositions were analysed and interpreted in terms of each species' foraging ecology in previous works (Pusineri et al. 2005, 2007, Chancollon et al. 2006, Ringelstein et al. 2006), but the dietary structure of the community and the possible mechanisms allowing feeding segregation within this community have not been investigated. Here, we will focus on issues at the community level. The objective is firstly to compare the feeding niches of the 5 species in the 3 main dimensions (trophic, temporal, spatial). Then, we will examine if, as seems to be the rule in most aquatic communities, feeding niche segregation is principally observed along the trophic dimension because of tight relationships between predator and prey sizes, or if the present community follows the trend found in other top predator communities showing a more complex pattern of feeding niche segregation.

\section{MATERIALS AND METHODS}

Origins and description of data. The present work is a meta-analysis of dietary data obtained previously (Pusineri et al. 2005, 2007, Chancollon et al. 2006, Ringelstein et al. 2006). All species were collected simultaneously and sympatrically (Fig. 1); all sampled individuals are considered independent as not more than 1 individual per species was taken from any particular drift-net haul. Stomachs were collected by fishery observers from animals caught or by-caught in commercial drift-nets. Sampling took place from June to August 1993 off the Bay of Biscay, from 39 to $50^{\circ} \mathrm{N}$ and 10 to $21^{\circ} \mathrm{W}$. The blue shark Prionace glauca ( $\mathrm{N}=$ 24 non-empty stomach contents) ranged from 75 to $212 \mathrm{~cm}$, with a mean body length of $123 \pm 34 \mathrm{~cm}$. Swordfish Xiphias gladius length ranged from 79 to $226 \mathrm{~cm}$ (mean lower jaw to fork length, FL = $142 \pm$ $43 \mathrm{~cm} ; \mathrm{N}=83$ non-empty stomach contents). Albacores Thunnus alalunga were 53 to $93 \mathrm{~cm}$ in length (FL = $69 \pm 7 \mathrm{~cm} ; \mathrm{N}=51$ non-empty stomach contents). Common Delphinus delphis and striped Stenella coerulaeoalba dolphins ranged from 101 to $221 \mathrm{~cm}$ (mean body length, $\mathrm{BL}=167 \pm 28 \mathrm{~cm} ; \mathrm{N}=61$ non-empty stomach contents) and from 94 to $230 \mathrm{~cm}(\mathrm{BL}=175 \pm 32 \mathrm{~cm}$; $\mathrm{N}=60$ non-empty stomach contents), respectively.

The diet of each species was determined following standard stomach content analysis methods aimed at quantifying the diet in terms of prey occurrence, relative abundance, reconstituted mass and size distribution (details in: Chancollon et al. 2006 for the swordfish, Pusineri et al. 2005 for the albacore, Pusineri et al. 2007 for the common dolphin and Ringelstein et al. 2006 for the striped dolphin). In brief, stomach contents were thawed and washed through a sieve of $0.2 \mathrm{~mm}$ mesh size; loose diagnostic parts (fish bones, otoliths and 


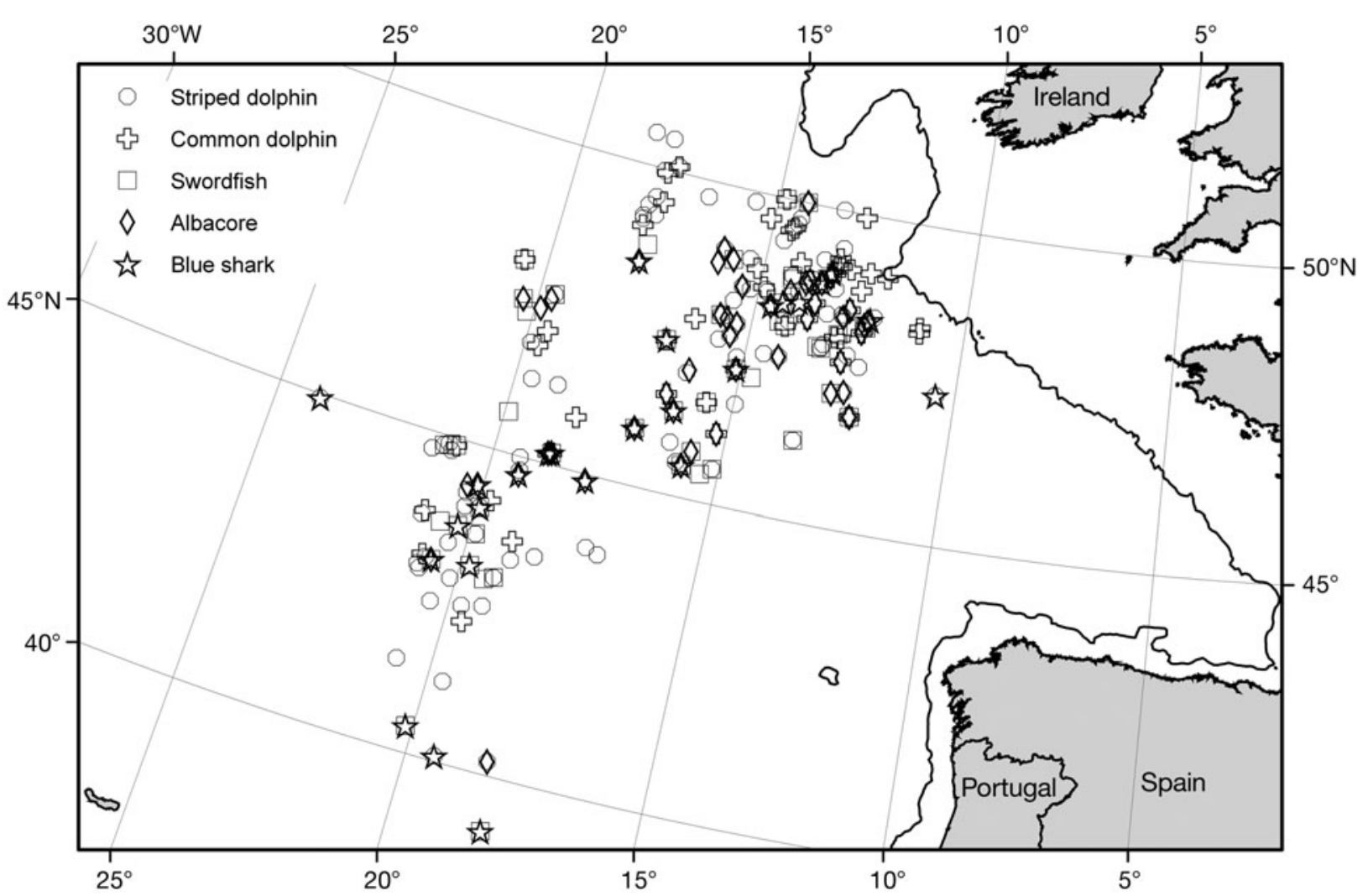

Fig. 1. Sampling area off the Bay of Biscay for albacore tuna Thunnus alalunga, blue shark Prionace glauca, common dolphin Delphinus delphis, swordfish Xiphias gladius and striped dolphin Stenella coerulaeoalba

cephalopod beaks) and fresh prey items were recovered and identified. Fish bones and otoliths were stored dry, whereas cephalopod beaks were kept in $70 \%$ ethanol. Each prey item was scored on a scale according to its degree of digestion; this allowed us to determine a fresh fraction within the total diet composition derived from all prey items (Pusineri et al. 2005). The number of individuals was determined as half the number of otoliths rounded up to the integer for fish and as the maximum number of lower or upper beaks for cephalopods. Diagnostic hard parts, mostly fish otoliths and squid beaks, were measured $( \pm 0.02 \mathrm{~mm})$. When $>50$ diagnostic remains were present for 1 prey taxon in a stomach, a sub-sample of 30 was measured. Individual prey body length and mass were calculated using published allometric relationships. Because dorsal mantle length (DML, the standard length measurement for squids) is a fairly poor indicator of squid total length (TL, including head and arms) we derived total length from TL/DML ratios obtained from published illustrations (Nesis 1987). The frequency of occurrence of a given prey taxon was calculated as the number of stomachs in which the taxon was observed. The relative abundance was assessed as the number of items found in the sample set. The reconstructed biomass was cal- culated as the product of the number of individuals and the average reconstituted body mass, in each stomach, summed throughout the sample set. Prey size distributions by number and by mass at sample level were weighted by the number or mass of individuals in the sample and summed to produce the overall size distributions of a prey species in the whole series of samples.

In the present study, we used diet compositions by mass at prey family level (Appendix 1), as well as the distributions of prey body lengths expressed as contributions by mass of each size class (from Pusineri et al. 2005, 2007, Chancollon et al. 2006, Ringelstein et al. 2006). Total mass composition was preferred to a mass composition of fresh remains only, because fresh remains were too scarce in the stomach content of the blue shark; we acknowledge that by doing this, the squid part of the diet is likely overestimated, but this bias would be similar in all predator species. The family level was preferred to the species level in data analyses to standardise the level of identification throughout the sample set and avoid biases in diversity that would be linked to differences in our capacity to identify species in the different prey categories (e.g. myctophid fish were identified to species level from the otolith, which would create many prey categories 
in the dolphins, whereas several other prey taxa can hardly be identified below family level, which potentially reduces measurable prey diversity).

Data analysis. Trophic dimension: The interspecific variability of the predator diet compositions by prey families was investigated by performing a factor analysis. Prey taxa occurring in $<10$ stomach contents were excluded from the analysis. Interspecific variability in diet compositions by prey length was investigated by comparing predator-prey length distributions.

Overlaps in diet composition by prey taxa or prey length among each pair of predators were determined by computing Morisita (1959) overlap indices (Eq. 1). This index varies between 0 (no overlap at all) and 1 (same prey array, each accounting for the same proportion of the diet in both predators):

$$
\mathrm{Mo}_{X Y}=\left(2 \Sigma_{i} X_{i} Y_{i}\right) /\left(D_{X}+D_{Y}\right) \cdot \Sigma_{i} X_{i} \cdot \Sigma_{i} Y_{i}
$$

where $x_{i}$ is the frequency of prey family (or prey length class) $i$ in the diet of Predator $\mathrm{X}$ and $y_{i}$ is the frequency of prey family (or prey length class) $i$ in the diet of Predator Y. Here, frequencies are relative frequencies so that the sample size does not influence the result. Data were by mass, and only families and length classes accounting for $>1 \% \mathrm{M}$ were considered. $D$ is the Simpson (1949) index of diversity:

$$
D_{x}=\left[\mathrm{S}_{i} x_{i} \cdot\left(x_{i}-1\right)\right] /\left(\mathrm{S}_{i} x_{i} \cdot \mathrm{S}_{i} x_{i}-1\right)
$$

Following Ross (1986), resource use was considered substantially segregated when overlap values were $<0.4$. The word 'substantially' is used instead of 'significantly' because the threshold used was empirically defined (Ross 1986) and does not constitute a statistical test.

Diet taxonomic diversity was estimated for each predator by the Shannon-Wiener index of diversity (ShI; Eq. 3), specific richness ( $s=$ number of prey taxa, here at family level) and equitability ( $\left.E_{\text {; Eq. }} 4\right)$.

$$
\begin{gathered}
\mathrm{ShI}=-\Sigma_{i}\left(m_{i} / M\right) \cdot \log _{2}\left(m_{i} / M\right) \\
E=\mathrm{ShI} \mathrm{ShI}_{\max }
\end{gathered}
$$

where $m_{i} / M$ is the proportion by mass of prey family $i$ in the predator diet and $\mathrm{ShI}_{\max }$ is the theoretical value of the Shannon-Wiener index if all prey families were present in equal proportion.

An explanatory diagram, the Costello (1990) diagram (modified by Amundsen et al. 1996), was built for each predator. This tool is used to graphically characterise diet variability of a predator by plotting preyspecific importance for each prey taxon ( $\% P_{i}$ Eq. 5) against frequency of occurrence $\left(\% \mathrm{Occ}_{i}\right.$ i Eq. 6$)$ on a 2-dimensional graph (see Fig. 4). In the upper lefthand corner of the diagram for each predator species, each prey species occurs rarely, but accounts for a large proportion of the diet when present; hence, if most prey species concentrate here, the predator is characterised by high between-individual and low within-individual variability. In the upper right-hand corner of each diagram, a single prey tends to be present in all individuals and to account for the total diet. In this case, all individuals rely on the same resource. In the lower right-hand corner of each diagram, prey species occur at high frequency, but each only accounts for a small proportion of the food when present. This suggests high within-individual variability in prey preference and low between-individual variability, since all individual predators prey upon the same species assemblage. Finally, in the lower lefthand corner of the separate diagrams, individual prey species display both a low occurrence and low relative importance when present. If most prey species concentrate here, the predator shows elevated within- and between-individual variability:

$$
\begin{gathered}
\% P_{i}=\left(\Sigma_{i} M_{i} / \Sigma_{t i} M_{t i}\right) \times 100 \\
\% \operatorname{Occ}_{i}=\left(n_{i} / N\right) \times 100
\end{gathered}
$$

where $M_{i}$ is the contribution (by mass in the present study) of prey taxa $i$ at family level to stomach content, $M_{t i}$ is the total stomach content weight in only those predators with prey $i$ in their stomach, $n_{i}$ is the number of stomachs in which prey taxon $i$ was found and $N$ is the total number of stomachs.

Temporal and spatial dimensions: Because all samples were collected at a fixed time (drift-nets were set at about 21:00 h and hauled at around 05:00 h), it was possible to infer some characteristics of the likely predator feeding rhythm following the steps below. In the course of the stomach content analysis, each prey was given a digestion condition code $(\mathrm{DCC} 1=$ more than half of flesh remains, DCC2 $=$ less than half of flesh remains, DCC3 = flesh fully digested, only loose, uneroded hard parts found (otoliths, beaks, exoskeletons), DCC4 = loose, eroded hard parts). Each prey family was classified into gross prey taxa and size categories (SF: small fish with BL $<10 \mathrm{~cm}$; MF: medium fish, $10 \mathrm{~cm}<\mathrm{BL}<30 \mathrm{~cm}$; LF: large fish, $\mathrm{BL}>30 \mathrm{~cm}$; SCE: small cephalopods with $\mathrm{BM}<50 \mathrm{~g}$; MCE: medium cephalopods, $50 \mathrm{~g}<\mathrm{BM}<200 \mathrm{~g}$; LCE: large cephalopods, BM > 200 g; CR: crustaceans). We used flesh digestion times (time to reach DCC3) estimated in vitro (Pusineri 2005) and in vivo for tunas (Olson \& Boggs 1986) and seals (Bigg \& Fawcett 1985) to determine when a prey category (SF, MF, LF, SCE, MCE, $\mathrm{LCE}$, or $\mathrm{CR}$ ) found in a given digestion state (DCC1, DCC2, DCC3, or DCC4) was more likely consumed (daylight, dusk, or night; Table 1). Combining these results with information on prey distribution in the water column (Table 2), it was possible to infer the most likely depth(s) and period(s) of main feeding activity for each predator. 
Table 1. Determination of approximate prey catch period for a given prey category at a given digestion state from the time period to reach DCC3 found in the literature. ND: no data; DCC1: more than half of flesh remains; DCC2: less than half of flesh remains; DCC3: flesh fully digested, only loose, uneroded hard parts found (otoliths, beaks, exoskeletons); DCC4: loose, eroded hard parts

\begin{tabular}{|c|c|c|c|c|c|c|c|}
\hline \multirow[t]{3}{*}{ Prey category } & \multicolumn{3}{|c|}{ Mean flesh digestion time } & \multirow{2}{*}{\multicolumn{4}{|c|}{$\begin{array}{c}\text { Approximate catch period for prey in } \\
\text { different digestion states }\end{array}$}} \\
\hline & In yellowfin & In seals & In vitro & & & & \\
\hline & $\begin{array}{l}\text { tuna (Olson \& } \\
\text { Boggs 1986) }\end{array}$ & $\begin{array}{c}\text { (Bigg \& } \\
\text { Fawcett 1985) }\end{array}$ & $\begin{array}{l}\text { (Pusineri } \\
\text { 2005) }\end{array}$ & DCC1 & $\mathrm{DCC} 2$ & DCC3 & $\mathrm{DCC} 4$ \\
\hline Small fish (SF) & $6 \mathrm{~h}$ & ND & $6 \mathrm{~h}$ & Night & Night & Dusk & Dusk \\
\hline Small cephalopods (SCE) & ND & $4 \mathrm{~h}$ & $6 \mathrm{~h}$ & Night & Night & Dusk & Unknown \\
\hline Crustaceans (CR) & ND & ND & $6 \mathrm{~h}$ & Night & Night & Dusk & Dusk \\
\hline Medium fish (MF) & $10-18 \mathrm{~h}$ & $12 \mathrm{~h}$ & $9 \mathrm{~h}$ & Night & Night/Dusk & Day & Day \\
\hline Medium cephalopods (MCE) & $10 \mathrm{~h}$ & ND & $12 \mathrm{~h}$ & Night & Night/Dusk & Day & Unknown \\
\hline Large fish (LF) & ND & ND & $14 \mathrm{~h}$ & Night/Dusk & Day & Day & Night before \\
\hline Large cephalopods (LCE) & ND & ND & $18 \mathrm{~h}$ & Night/Dusk & Day & Day & Unknown \\
\hline
\end{tabular}

Table 2. Prey profile and vertical range of the main prey taxa. Small fish are $<10 \mathrm{~cm}$, medium fish are from 10 to $30 \mathrm{~cm}$, large fish are $>30 \mathrm{~cm}$, small cephalopods are $<50 \mathrm{~g}$, medium cephalopods are from 50 to $200 \mathrm{~g}$, large cephalopods are $>200 \mathrm{~g}$ (Roper \& Young 1975, Roe et al. 1984, Whitehead et al. 1989, Guerra 1992)

\begin{tabular}{|lll|}
\hline Prey family & Prey profile & Prey vertical range \\
\hline $\begin{array}{l}\text { Sternoptichidae } \\
\text { Myctophidae }\end{array}$ & Small schooling fish & Mesopelagic, day; meso-epipelagic, night \\
Paralepididae & $\begin{array}{l}\text { Small schooling fish } \\
\text { Large fish (adults) in swordfish, medium fish } \\
\text { (juveniles) otherwise; single or in small schools }\end{array}$ & Mesopelagic, day; meso-epipelagic, night \\
Scomberesocidae & Medium schooling fish & Edults mesopelagic, juveniles epipelagic \\
Bramidae & Large fish; in small schools & Epic \\
Trachipteridae & Large solitary fish & Epipelagic \\
Alloposidae & Medium cephalopod & Mesopelagic \\
Onychoteuthidae & Medium cephalopods in shark (adults), & Mesopelagic \\
small cephalopods otherwise (juveniles) & Mesopelagic, day; meso-epipelagic, night \\
Gonatidae & Medium cephalopods in shark (adults), & \\
Histioteuthidae & small cephalopods otherwise (juveniles) & Mesopelagic, day; meso-epipelagic, night \\
Ommastrephidae & Small cephalopods in dolphins (juveniles), & Mesopelagic, day; meso-epipelagic, night \\
medium cephalopods otherwise (adults) & Large cephalopods in swordfish, & Mesopelagic, day; meso-epipelagic, night \\
shiroteuthidae & Small cepalopods otherwise & Mesopelagic, day; meso-epipelagic, night \\
Cranchiidae & Small cephalopods & Mesopelagic, day; meso-epipelagic, night \\
\hline
\end{tabular}

\section{RESULTS}

\section{Trophic dimension: segregation according to prey taxa}

The factorial analysis segregated 4 groups of predators: the blue shark Prionace glauca, the swordfish Xiphias gladius, the albacore Thunnus alalunga and the 2 dolphin species Delphinus delphis and Stenella coerulaeoalba (Fig. 2A). Overall, the 2 dolphins appeared tightly clustered in the middle of the plot, whereas the blue shark, the swordfish and the albacore were spread out in opposite directions. The blue shark was characterised by a high relative proportion by mass of ocythoid, alloposid and histioteuthid cephalopods, as well as some gelatinous plankters. The swordfish consumed a high proportion of ommastrephid and gonatid cephalopods along with trachipterid, bramid and paralepidid fish. The albacore diet showed high proportions of scomberesocid and sternoptychid fish, gonatid cephalopods and euphausiid crustaceans. The dolphins were characterised by a high proportion of several species of fish, such as myctophids, chauliodontids, stomiids, or bathylagids; of cephalopods, such as cranchiids, gonatids, or histioteuthids; and of crustaceans, such as oplophorids, pasiphaeids, or peneids. A second-factor 

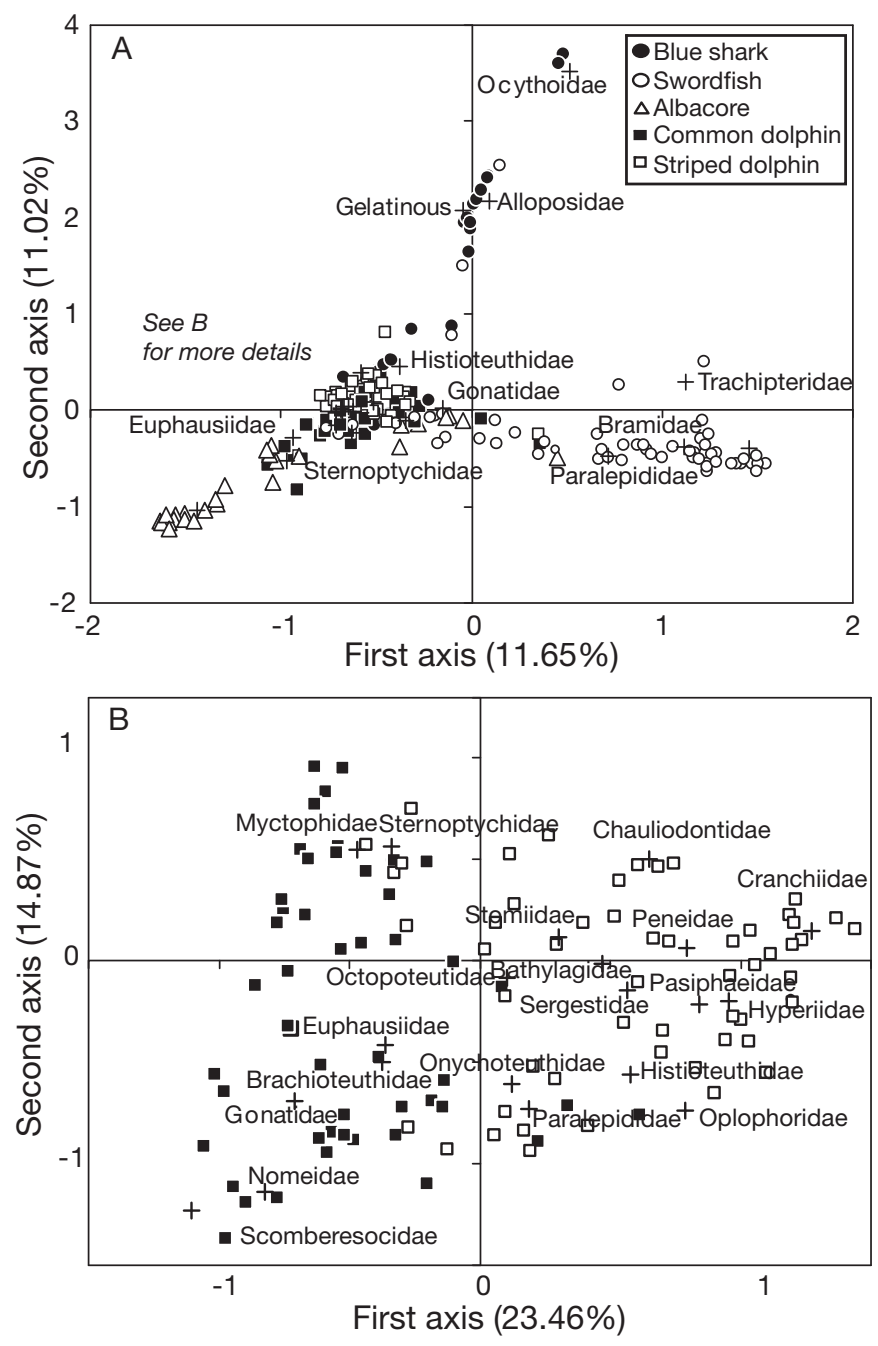

Fig. 2. Factor analysis of dietary composition by mass for: (A) all predators and (B) only the 2 dolphin species. Data are the composition by mass at the family level of each stomach content analysis, computed with only the common and striped dolphins, showed that dietary differences might be identified between the 2 species (Fig. 2B). Indeed, the common dolphin was characterised by a higher proportion of myctophid, scomberesocid and nomeid fish and gonatid cephalopods, while the striped dolphin consumed a higher proportion of cranchiid and histioteuthid cephalopods, crustaceans (peneids, oplophorids, pasiphaeids, etc.) and chauliodontid fish.

The trophic niches were substantially segregated $(\mathrm{Mo}<0.4)$ between all pairs of predator species, except for the 2 dolphins that showed an overlap index of as much as 0.82 (Table 3 ).

\section{Trophic dimension: segregation according to prey length}

The blue shark prey ranged from 2 to $152 \mathrm{~cm}$, but $80 \%$ by mass of its diet was accounted for by prey individuals in a range from 8 to $63 \mathrm{~cm}$. Similarly, the swordfish prey ranged from 1 to $142 \mathrm{~cm}$, but $90 \%$ by mass of the food was provided by individuals from 10 to $80 \mathrm{~cm}$. The common dolphin, striped dolphin and albacore prey ranged from 1 to 68,3 to 54 and 1 to $23 \mathrm{~cm}$, respectively (Fig. 3). Prey ranging between 3 and $22 \mathrm{~cm}$ represented $>80 \%$ by mass of the prey length distributions of these 3 species.

Lower than 0.4 overlaps in prey size range were found only between albacore and blue shark and between albacore and swordfish (Table 3). Four pairs of predators showed considerable overlap in prey size ranges: the common and striped dolphins $(\mathrm{Mo}=0.96$; Table 3), the common dolphin and the albacore (Mo = $0.88)$, the striped dolphin and the albacore $(\mathrm{Mo}=0.82$ ) and to a lesser extent the swordfish and the blue shark $(\mathrm{Mo}=0.65)$.

Table 3. Niche overlaps in the trophic dimension. Data are diet contribution by mass of either prey families (above diagonal line) or prey length classes (below diagonal line). In parentheses are the $95 \%$ confidence interval of each overlap index. Bold print denotes 'substantial' overlap (see details in 'Materials and methods' section). For full taxonomic names of predators, see Fig. 1 legend

\begin{tabular}{|c|c|c|c|c|c|}
\hline & Blue shark & Swordfish & Albacore & Common dolphin & Striped dolphin \\
\hline Blue shark & & $\begin{array}{c}0.22 \\
(0.13-0.31)\end{array}$ & $\begin{array}{c}0.17 \\
(0.04-0.30)\end{array}$ & $\begin{array}{c}0.27 \\
(0.17-0.36)\end{array}$ & $\begin{array}{c}0.28 \\
(0.19-0.36)\end{array}$ \\
\hline Swordfish & $\begin{array}{c}0.65 \\
(0.51-0.75)\end{array}$ & & $\begin{array}{c}0.26 \\
(0.19-0.33)\end{array}$ & $\begin{array}{c}0.31 \\
(0.24-0.40)\end{array}$ & $\begin{array}{c}0.25 \\
(0.19-0.31)\end{array}$ \\
\hline Albacore & $\begin{array}{c}0.35 \\
(0.20-0.51)\end{array}$ & $\begin{array}{c}0.33 \\
(0.25-0.42)\end{array}$ & & $\begin{array}{c}0.39 \\
(0.31-0.46)\end{array}$ & $\begin{array}{c}0.17 \\
(0.13-0.22)\end{array}$ \\
\hline Common dolphin & $\begin{array}{c}0.51 \\
(0.34-0.68)\end{array}$ & $\begin{array}{c}0.46 \\
(038-0.56)\end{array}$ & $\begin{array}{c}0.88 \\
(0.83-0.91)\end{array}$ & & $\begin{array}{c}0.82 \\
(0.75-0.87)\end{array}$ \\
\hline Striped dolphin & $\begin{array}{c}0.55 \\
(0.38-0.70)\end{array}$ & $\begin{array}{c}0.48 \\
(0.40-0.55)\end{array}$ & $\begin{array}{c}0.82 \\
(0.77-0.87)\end{array}$ & $\begin{array}{c}0.96 \\
(0.94-0.98)\end{array}$ & \\
\hline
\end{tabular}




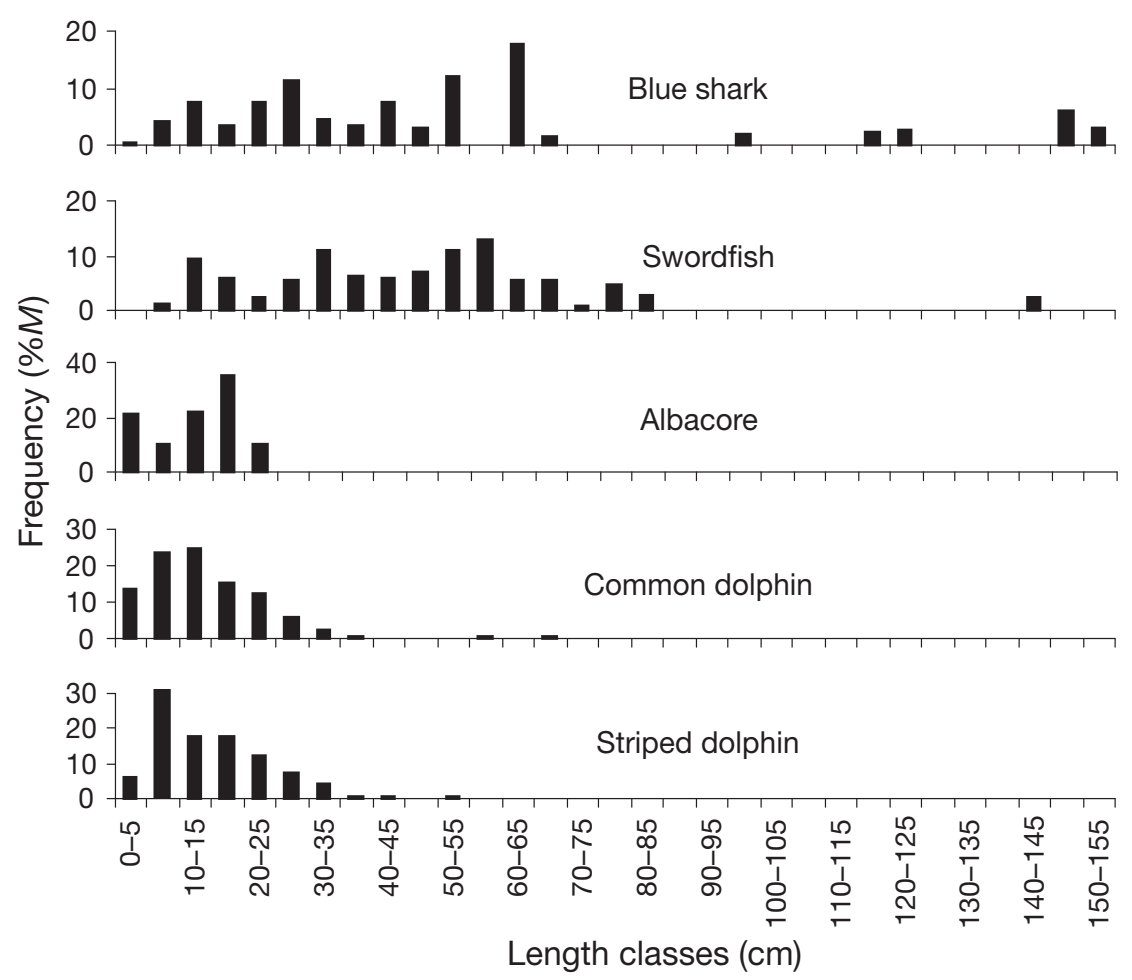

Fig. 3. Prey body length distribution by mass $(\% M)$. Prey lengths are standard lengths for fish, total lengths for cephalopods and total lengths without rostrum for crustaceans

\section{Trophic dimension: diet diversity and variability}

The blue shark, the swordfish and the albacore diets showed the lowest diversity (Fig. 4). Each of these species had only 1 preferred prey $(>33 \%$ in occurrence and specific importance): alloposids, ommastrephids and scomberesocids, respectively (Fig. 5). Apart from these prey taxa, a few prey occurred rarely, but accounted for a large proportion of the diet when present (upper left-hand corner of Costello diagrams: onychoteuthids and ocythoids for the blue shark, bramids and trachipterids for the swordfish, gonatids and octopoteuthids for the albacore), a few other prey occurred at high frequency, but only accounted for a small proportion of the food when present (lower right-hand corner: histioteuthids and cranchiids for the blue shark, gonatids and myctophids for the swordfish, sternoptychids and paralepids for albacores) and several prey were neither frequently preyed upon nor abundant when present. Hence, the general diet variability of these species resulted from a combination of within- and betweenindividual variability.

The 2 dolphins both had a preferred prey: myctophids for the common dolphin and cranchiids for the striped dolphin, but their diet was much more variable than that of the other species (Fig. 4). Indeed, they had the largest prey diversity, and their diets were made of many prey taxa that ranged from rare to very frequent, but that never made an important part of the diet by mass when present. This suggested low betweenindividual variability and a high within-individual variability.

\section{Temporal and spatial dimensions}

Most of the prey consumed by the blue shark were found in digested conditions, mainly including largesized ocythoid cephalopods in DCC4 or medium-sized alloposid, gonatid, histioteuthid cephalopods in DCC3 or DCC4 (from Fig. 5). The absence of squid remains in DCC fresher than 3 suggests that little feeding is likely to occur during the night (from Table 1). Furthermore, those prey items were likely caught in the mesopelagic layer as they are usually reported to be at such depths during the day (from Table 2). Following a similar step, it was inferred that the swordfish was likely to consume large bramid fish both during day and night (DCC1 to 4; Fig. 5, and from Table 1) in epipelagic waters (from Table 2), large adult paralepid fish during day and night (DCC1 to 4; Fig. 5) at mesopelagic depth, large trachipterid fish diurnally (DCC2; Fig. 5) in mesopelagic waters, small gonatid 


\begin{tabular}{|l|ccc|}
\hline \multicolumn{1}{|c|}{ Diversity } & Shl & $E$ & $S$ \\
\hline Blueshark & 2.10 & 0.6 & 11 \\
Swordfish & 1.90 & 0.4 & 21 \\
Albacore & 2.10 & 0.6 & 10 \\
$\begin{array}{l}\text { Common } \\
\text { dolphin }\end{array}$ & 2.60 & 0.5 & 28 \\
$\begin{array}{l}\text { Striped } \\
\text { dolphin }\end{array}$ & 3.00 & 0.6 & 28 \\
\hline
\end{tabular}
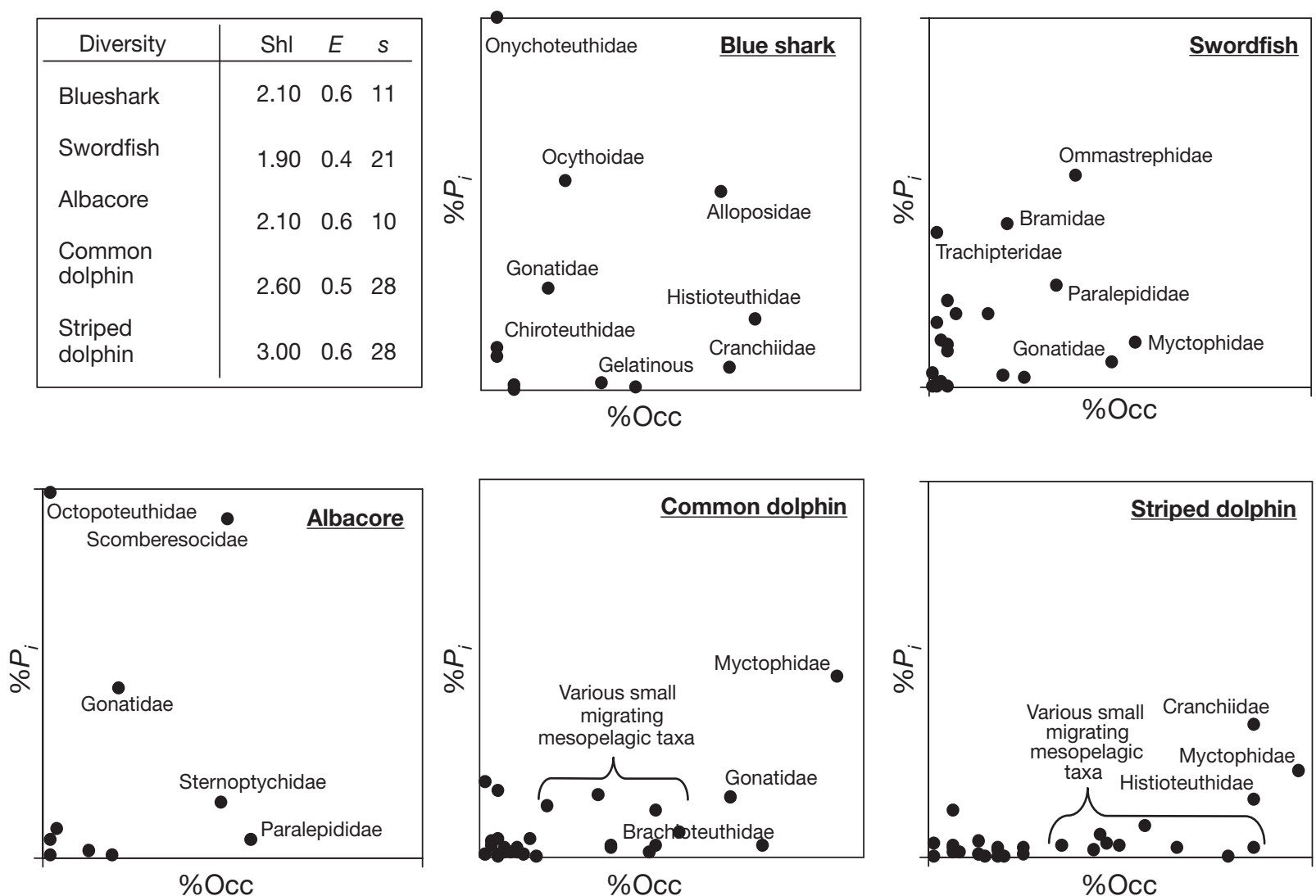

Fig. 4. Prey diversity indices, and Costello diagrams for blue shark, swordfish, albacore, common dolphin and striped dolphin. ShI: Shannon diversity index; $E$ : equitability index; $S$ : species richness index. Diagrams characterise diet variability of a predator by plotting prey-specific importance of each prey taxon (\% $P_{i i}$ Eq. 5) against frequency of occurrence (\%Occ; Eq. 6). For clarity, only the most important prey families are labelled. For further explanation see 'Materials and methods; Data analysis'

cephalopods nocturnally (DCC2 and 3; Fig. 5) in the epipelagic layer and, finally, large ommastrephid cephalopods during daylight in the mesopelagic layer (DCC3; Fig. 5) and at night in the epipelagic layer (DCC1; Fig. 5, and from Table 2). The albacore would consume small sternoptychid fish at dusk (DCC4; Fig. 5) in the epipelagic layer, medium scomberesocids and juvenile paralepid fish at anytime (DCC1 to 4; Fig. 5) in the epipelagic layer and small gonatid cephalopods at night (DCC2; Fig. 5) in the epipelagic layer. The common dolphin is likely to prey essentially on small myctophid fish at dusk (DCC4; Fig. 5) in the epipelagic layer, on medium scomberesocid fish during the day (DCC4; Fig. 5) in the epipelagic layer and on small gonatids, cranchiids and histioteuthids at dusk and night (DCC1 to 3 ; Fig. 5) in the epipelagic layer (from Table 2). The striped dolphin seems to prey mainly on small myctophid fish at dusk (DCC3 and 4 ; Fig. 5) in the epipelagic layer and on small cranchiid, histioteuthid and onychoteuthid cephalopods at night (DCC2; Fig. 5) in the epipelagic layer (from Table 2).

\section{DISCUSSION}

\section{Methodological comments}

The present study examined the amount of overlap along the main dimensions of the feeding niches of 5 Northeast Atlantic oceanic top predators. In brief, the blue shark Prionace glauca, the albacore Thunnus alalunga and the swordfish Xiphias gladius segregated fairly well from each other and from the 2 dolphins Delphinus delphis and Stenella coerulaeoalba in terms of prey taxa, whereas the 2 dolphins showed considerable overlap in this respect. In terms of prey sizes, substantial overlap was found between the blue shark and the swordfish that both extensively fed on prey items larger than $24 \mathrm{~cm}$, but differed from the 2 dolphins and the albacore, which, in turn, overlapped considerably in the range from 3 to $22 \mathrm{~cm}$. Spatio-temporally, again the same 2 groupings were inferred, with the blue shark and the swordfish being predominantly diurnal mesopelagic predators and the albacore and the dolphins being mostly nocturnal or dusk epipelagic feed- 


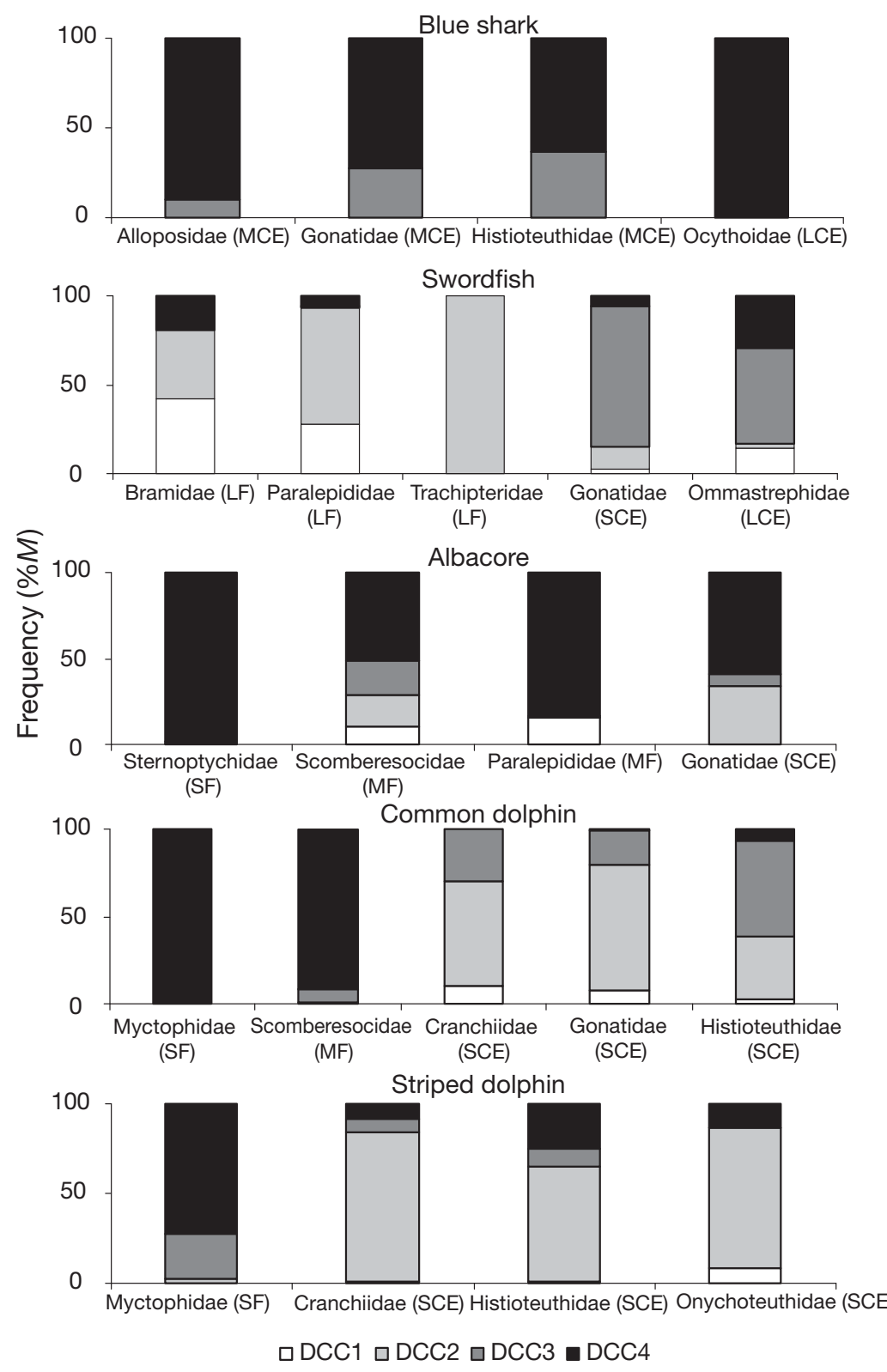

Fig. 5. Digestion state of the main prey of each predator. Proportions are given as relative proportions by mass $(\% M)$. DCC: digestion condition code; SF: small fish; MF: medium fish; LF: large fish; SCE: small cephalopod; MCE: medium cephalopod

ers. Finally, it appeared that prey diversity was higher in the 2 dolphins than in the shark and the 2 teleosts and, also, that the 2 dolphins typically showed a lower inter-individual variability and a higher amongindividual diversity in stomach content composition.

The stronger points in this study are all variables that were directly measured from the analysis of the stomach contents (prey diversity, composition and size range). Indeed, although all sources of uncertainty associated with stomach content analysis were fully acknowledged (see discussion in Pusineri et al. 2005, Chancollon et al. 2006), it must be underlined here that the samples were collected during fishery operations and were therefore from active healthy animals, likely to have experienced a normal foraging activity the day before. Also, the fishery involved used a passive gear targeting the albacore, which is not part of the diet of any of the predators studied here; therefore, the conditions of sampling are considered unlikely to bias the diet compositions markedly. Weaker points, however, are those variables that were not directly measured but were indirectly inferred from prey species composition and from prey item digestion condition (foraging depth and daily rhythm). Indeed, information on the dynamics of the vertical distribution of pelagic organisms is sketchy, with only one comprehensive study (Roe et al. 1984) available in the area, and the understanding of prey transit and digestion time is even more speculative. Furthermore, as the predators were all caught at night and stomach content analysis has a poor temporal integration, we may have a limited representation of the daylight feeding behaviour of these animals. For example, we would not be able to detect small prey consumed at day, as they would be digested in only a few hours. However, in the absence of in situ measurements of diel changes in foraging activity, notably by using individual telemetry devices, these preliminary inferences are useful because they shed some light on these aspects. Finally, it must be highlighted that because all predators were sampled sympatrically (same gear, same depth, same area, same period; see 'Materials and methods' section and Fig. 1), they were all living in identical conditions in terms of prey availability; therefore, the observed differences in their diet solely reflect differences in species-specific foraging strategies.

\section{Comparisons with previous work}

Few previous studies dealt with comparable species assemblages of oceanic top predators and the examined variables were not necessarily the same; however, the comparison of their general conclusions is still informative. In the East Tropical Pacific Ocean (ETP), the pelagic dolphins Stenella longirostris and S. atten- 
uata had substantial dietary overlap with the yellowfin tuna Thunnus albacares, caught in mixed feeding aggregations (Perrin et al. 1973). They showed similar niche breadths, the same dominant prey speciespresumably the binding species that triggered these aggregations - but partly differed in the contributions of secondary prey species, foraging rhythm and maximum depth. An assemblage of yellowfin and blueeyed tunas $T$. albacares and $T$. obesus in the tropical Indian Ocean showed an almost complete overlap, with both species feeding on the same crustacean species assemblage, when sampled by purse seine in the surface layer, but a clear segregation was found when the 2 species were sampled by long-lines at the species' preferential depths on either sides of the thermocline (Potier et al. 2004). Common and striped dolphins off South Africa displayed only partial dietary overlap, with the striped dolphin having a broader feeding niche and taking more squids than did the common dolphin (Sekiguchi et al. 1992). In Azorean waters, the tunas T. albacares and T. obesus associate with dolphins Stenella frontalis, D. delphis and Tursiops truncatus, to forage collectively on the same fish schools (Clua \& Grosvalet 2001), quite similarly to the mixed aggregations studied in the ETP by Perrin et al. (1973). In the same region, it was found that squid species preyed upon by the blue shark mostly corresponded to ammoniacal squids from habitats deeper than $500 \mathrm{~m}$, whereas those found in the swordfish were essentially muscular and energy-richer species from shallower depths (Clarke et al. 1996). The same applies to the present results, with more ommastrephid squids and more bramid and paralepidid fish in the swordfish and more histioteuthid and alloposid cephalopods in the blue shark. Off the Bay of Biscay, in the Northeast Atlantic, an approach based on heavy metal burdens and stable isotopes, both transmitted to predators by food, suggested partial niche segregation between albacore and dolphins, but extensive overlap among dolphins (Das et al. 2000).

\section{Feeding strategies}

\section{Constraints}

The 5 predators examined in this community study were not all similarly sized, shaped, or physiologically constrained in relation to their foraging capacities. In terms of body length, the albacore was much smaller than the other 4 species, being only represented by juveniles migrating in the summer (Bard 1981); among the other species, the 2 dolphins were the largest. These differences in body length are drastically exacerbated when one considers average individual body mass: from a few kilograms in albacores up to $>100 \mathrm{~kg}$ in dolphins. Even if their routine, sustained and maximum instantaneous swimming speeds are only fragmentarily known and probably vary among species, all species can be considered as sustained or at least fast burst swimmers (Magnuson 1978, Block et al. 1992, Williams 2002).

Mouth shapes and conformations are diversified. The mouth is very broad, ventrally opened and equipped with numerous hook-shaped teeth and a large expandable pharynx in the blue shark. It is terminally opened and bears no or only small teeth in the swordfish and the albacore; in the former, it is unclear whether the very sharp sword has any role in foraging (Palko et al. 1981, Stillwell \& Kohler 1985, Clarke et al. 1995). Finally, the dolphin mouth is shaped in an elongated narrow rostrum, with longitudinally oriented rows of conical teeth, and is followed with a pharynx that is crossed by the upper respiratory tract in a cartilaginous structure called the goose beak, which can be an obstacle to the ingestion of very large prey. In this context, at similar body size, sharks would be better fitted to grasp and tear off bits of comparatively larger prey, and dolphins would be constrained to feed on smaller ones.

Other constraints that largely differ among the members of this community are energy requirements and dependence on the surface layer. The carcharinid blue shark is an ectotherm whose activity level largely depends on ambient temperature (Purves et al. 1992). Swordfish display some degree of regional endothermy, allowing the central nervous system and eyes to be maintained 10 to $15^{\circ} \mathrm{C}$ above ambient temperature; this allows a visual temporal resolution up to 10 times higher than in strictly ectothermic fish, a dramatic advantage in hunting mobile prey (Fritsches et al. 2005). Tunas probably achieve the highest level of endothermy in teleosts, as the largest species maintains its body temperature at about $31^{\circ} \mathrm{C}$ over a range of water temperatures from 2 to $26^{\circ} \mathrm{C}$ (review in Bernal et al. 2001). The albacore maintains a core temperature of $21^{\circ} \mathrm{C}$ throughout a range of seawater temperatures from 11 to $18^{\circ} \mathrm{C}$ (Alonso et al. 2005). Even if this core temperature is much lower than in larger tunas and mammals, this is likely to represent a major energy cost, as albacores have no blubber insuring thermal insulation and, at least when they are young, their body surface to body volume ratio is unfavourable for heat conservation compared to that in larger tunas and dolphins. Being mammals, dolphins maintain a body temperature of about $37^{\circ} \mathrm{C}$ irrespective of the water temperature (Elsner 1999).

As a consequence of these fundamental physiological differences, energy needs and thus food requirements differ largely from the energy-cheapest life style of the blue shark to the most expensive life style of the 
dolphins. It has been estimated that an average blue shark would need about 1.4 times its own body mass as an annual food intake, whereas the same ratio would be from 3.4 to 5.8 for the swordfish, 11 to 36 in tunas (review in Stillwell \& Kohler 1985) and 15 to 36 for the common dolphin (C. Pusineri et al. unpubl. data).

Finally, their ability to explore the depth of the ocean is also variously developed. Dolphins have to breathe air at the surface between foraging dives; therefore, they must find a trade-off between breath-hold capacity (5 to $10 \mathrm{~min}$; Elsner 1999), costs of travelling to foraging depth and the benefits that results from time available and prey density or catchability at foraging depth. Their diving performances have seldom been documented, but are thought to be mostly restricted to the upper $200 \mathrm{~m}$ (Evans 1994, Archer 2002). For physiological reasons related to core temperature control and to the development of the gas bladder, juvenile albacores are also restricted to the $100 \mathrm{~m}$ surface layer (Aloncle \& Delaporte 1973, Alonso et al. 2005). No similar major constraints seem to apply to either the blue shark or the swordfish; accordingly, they forage as deep as $600 \mathrm{~m}$ (Carey \& Robinson 1981, Carey \& Scharold 1990, Matsumoto et al. 2003).

\section{Responses}

The most crucial constraints that best split the Northeast Atlantic top predator community were their specific energy requirements and diving abilities: clearly the blue shark and swordfish have limited to intermediate food requirements and may dive to mesopelagic depths, whereas the albacore and dolphins have elevated food requirements and would be constrained to the epipelagic layer. This concurs with several groupings made earlier in this study when analysing overlaps along various dimensions of the feeding niches.

The albacore and dolphins have to face large metabolic needs associated with regional or total endothermy, respectively, and therefore must forage on highly predictable resources. Additionally, they are physiologically bound to the surface and therefore constrained to explore only epipelagic depths. Consequently, they have to concentrate on a predictable food source in the upper 100 to $200 \mathrm{~m}$ water layer. In the oceanic Northeast Atlantic, the migrating mesopelagic fauna constitutes such a predictable and abundant food resource that it is exploited by all 3 species. These forage organisms are made of many different species of crustaceans, cephalopods and fish, with a common prey profile: small, gregarious and vertically migrating forms. They live in dense swarms at depth during daylight when they constitute the deep scattering layer (DSL); they migrate up to epipelagic depth at dusk, still in dense shoals, but tend to disperse in the surface layer during the night as a result of their own feeding behaviour (Roper \& Young 1975, Roe et al. 1984). Therefore, dusk would be the most favourable period for surface-bound predators, and both tunas and dolphins have developed tactics of collective hunting, which allows them to maintain their prey in dense concentrations (Trillmich 2002). Hence, the low inter-individual and high within-individual variability in diet composition that was observed in dolphins would result from all the individuals of a given predator species targeting grossly the same food source, composed of a mixture of different species. However, some degree of dietary segregation is achieved between albacore and dolphins and, to a much less extent, among dolphins as well. It is proposed that this segregation would express some differences in foraging depth and time relative to the vertical migration of the different components of the DSL that act at a fine spatio-temporal scale and could only be documented by using individual telemetry.

The blue shark and, to a lesser extent, the swordfish have energetically cheaper life styles than those of dolphins and albacore; therefore, their food requirements are more limited. They could live on smaller amounts of food per day or withstand extended periods of fasting, albeit, no specific reference to their real fasting abilities was found; additionally, they are not physiologically bound to the surface layer. Consequently, they are better fitted to exploring the depleted regions and depths of the ocean, looking for scattered food resources. In the present work, these 2 species were both characterised by feeding mostly on large, non-gregarious prey, presumably caught diurnally at depth. Both are reported to forage solitarily and to take large to very large prey items that they can reduce into pieces of edible size (Palko et al. 1981, Stillwell \& Kohler 1985, Whitehead et al. 1989, Clarke et al. 1995). In this strategy, the blue shark is obviously more extreme than the swordfish. This is in line with the presence of deeper living prey species of lower calorific value in its diet than that found in swordfish, which incorporates comparatively more epipelagic fish and more muscular squids in its food (Clarke et al. 1995, 1996, present study), with a larger proportion caught at night (present study).

\section{Conclusion}

It appears that the Northeast Atlantic community of oceanic top predators is primarily structured as a response to energetic and diving constraints faced by the different predator species. Each species develops its own feeding niche within the space defined by its physical and physiological characteristics. The blue 
shark seems to develop to the extreme a strategy based on low food requirements that can be met by foraging on large, scattered and low-energy prey types. The swordfish would have intermediate food requirements, and it incorporates more epipelagic and energy-rich prey species. Finally, the albacore and dolphins would be physiologically constrained to the epipelagic layer and would have high energy needs that can only be satisfied by exploiting organisms of the DSL as they migrate up to the surface at dusk and night; among them, some degree of segregation is observed in terms of diet composition (quite clearly in the case of the albacore compared to the dolphins, not so much among the dolphins), but not in terms of prey sizes. As a consequence, within the whole community, segregation can be achieved by a complex combination of characteristics and, in contrast to many fish community studies, the relationship between predator and prey size is weak and is not the main structuring factor.

Acknowledgements. This study was funded by the Ifremer and CNRS through the research project Chantier Golfe de Gascogne, Programme National d'Environnement Côtier. We are particularly grateful to M. K. Alonso for his help on niche segregation computing, and F. Ménard for his helpful and interesting suggestions on an earlier draft of the manuscript.

\section{LITERATURE CITED}

Aloncle H, Delaporte F (1973) Rythmes alimentaires et circadiens chez le germon Thunnus alalunga dans le Nord-Est atlantique. PhD thesis, Paris VI, Paris

Alonso C, Arrizabalaga H, Restrepo VR (2005) Contribution of a chapter on albacore tuna for the revised ICCAT field manual. Collect Vol Sci Pap ICCAT 58:1646-1669

Amundsen PA, Gabler HM, Staldvik FJ (1996) A new approach to graphical analysis of feeding strategy from stomach contents data-modification of the Costello (1990) method. J Fish Biol 48:607-614

Archer FI (2002) Striped dolphin. In: Perrin WF, Wüsrig B, Thewissen JGM (eds) Encyclopedia of marine mammals. Academic Press, New York, p 1201-1203

Bard FX (1981) Le thon germon (Thunnus alalunga) de l'océan Atlantique. PhD dissertation, Paris V, Paris

Bernal D, Dickson KA, Shadwick RE, Graham JB (2001) Review: analysis of the evolutionary convergence for high performance swimming in lamnid sharks and tunas. Comp Biochem Physiol A 129:695-726

Bigg MA, Fawcett I (1985) Two biases in diet determination of northern fur seals. In: Beddington JR, Beverton JH, Lavigne DM (eds) Marine mammals and fisheries. George Allen and Unwin, Boston, MA, p 277-282

Block BA, Booth DT, Carey FG (1992) Direct measurement of swimming speed and depth of bleu marlin. J Exp Biol 166: 267-284

Bulman CM, He X, Koslow JA (2002) Trophic ecology of the mid-slope demersal fish community off southern Tasmania, Australia. Mar Freshw Res 53:59-72

Cabral HN, Lopes M, Loeper R (2002) Trophic niche overlap between flatfishes in a nursery area on the Portuguese coast. Sci Mar 66:293-300

Carey FG, Robinson BH (1981) Daily patterns in the activities of swordfish, Xiphias gladius, observed by acoustic tele- metry. Fish Bull (Wash DC) 79:277-292

Carey FG, Scharold JV (1990) Movements of blue sharks (Prionace glauca) in depth and course. Mar Biol 106:329-342

Chancollon O, Pusineri C, Ridoux V (2007) Food and feeding ecology of the Northeast Atlantic swordfish (Xiphias gladius), off the Bay of Biscay. ICES J Mar Sci 63:1075-1085

Clarke MR, Clarke DC, Martins HR, DaSilva HM (1995) The diet of the swordfish (Xiphias gladius) in Azorean waters. Arquipélago Life Mar Sci 13:53-69

Clarke MR, Clarke DC, Martins HR, DaSilva HM (1996) The diet of the blue shark (Prionace glauca L.) in azorean waters. Arquipélago. Life Mar Sci 14A:41-56

Clua E, Grosvalet F (2001) Mixed-species feeding aggregation of dolphins, large tunas and seabirds in the Azores. Aquat Living Resour 14:11-18

Costello MJ (1990) Predator feeding strategy and prey importance: a new graphical analysis. J Fish Biol 36:261-263

Croxall JP, Prince PA, Reid K (1997) Dietary segregation of krill-eating South Georgia seabirds. J Zool (Lond) 242: 531-556

Cury P, Shannon L, Shin YJ (2001) The functioning of marine ecosystems. In: Proceedings of the Reykjavik conference on responsible fisheries in the marine ecosystem. ftp://ftp. fao.org/fi/document/reykjavik/pdf/07Cury.pdf

Das K, Lepoint G, Loizeau V, Debacker V, Dauby P, Bouquegneau JM (2000) Tuna and dolphin associations in the Northeast Atlantic: evidence for different ecological niches from stable isotope and heavy metal measurements. Mar Pollut Bull 40:102?109

> Dellinger T, Trillmich F (1999) Fish prey of the sympatric Galapagos fur seals and sea lions: seasonal variation and niche separation. Can J Zool 77:1204-1216

Diamond AW (1983) Feeding overlap in some tropical and temperate seabird communities. Stud Avian Biol 8:24-46

Elsner R (1999) Living in water: solutions to physiological problems. In: Reynolds JE, Rommel SA (eds) Biology of marine mammals. Smithsonian Institution Press, London, p 73-116

Evans WE (1994) Common dolphin, white-bellied porpoise, Delphinus delphis, Linnaeus, 1758. In: Ridgway SH, Harrison R (eds) Handbook of marine mammals, Vol 5: the first book of dolphins. University Press, London, p 191-224

FAO (Food and Agriculture Organization) (2004) The state of world fishery and aquaculture. FAO, Rome

Franeker JA, Williams R, Imber MJ, Wolff WJ (2001) Diet and foraging ecology of southern fulmar Fulmarus glacialoides, antarctic petrel Thalassoica antarctica, Cape petrel Daption capense and snow petrels Pagodroma nivea spp. on Ardery Island, Wilkes land, Antarctica. In: Franeker JA (ed) Mirrors in ice: fulmarine petrels and Antarctic ecosystems. PhD dissertation, University of Groningen

Fritsches KA, Brill RW, Warrant EJ (eds) Warm eyes provide superior vision in swordfishes. Curr Biol 15:55-58

Garcia SM, Zerbi A, Aliaume C, Do Chi T, Lasserre G (2003) The ecosystem approach to fisheries. Issues, terminology, principles, institutional foundations, implementation and outlook. FAO Fish Tech Pap 443

Guerra A (1992) Mollusca, Cephalopoda. Museo Nacional de Ciencias Naturales, Madrid

Harrison CS, Hida TS, Seki MP (1983) Hawaiian seabird feeding ecology. Wildl Monogr 85:1-71

Hopkins TL, Sutton TT, Lancraft TM (1996) The trophic structure and predation impact of a low latitude midwater fish assemblage. Prog Oceanogr 38:205-239

Hutchinson GE (1957) A treatise on limnology, Vol 1. Geography, physics, chemistry. Wiley, New York 
Jennings S, Pinnegar JK, Polunin VC, Boon TW (2001) Weak cross-species relationships between body size and trophic level belie powerful size-based trophic structuring in fish communities. J Anim Ecol 70:934-944

Karpouzi VS, Stergiou KI (2003) The relationships between mouth size and shape and body length for 18 species of marine fishes and their trophic implications. J Fish Biol 62:1353-1365

Lundvall D, Svanback R, Persson L, Bystrom P (1999) Sizedependent predation in piscivores: interactions between predator foraging and prey avoidance abilities. Can J Fish Aquat Sci 56:1285-1292

Magnuson JJ (1978) Locomotion by scombrids fish, morphology and behavior. Fish Physiol 7:239-313

Matsumoto T, Saito H, Miyabe N (2003) Report of observer program for Japenese tuna logline fishery in the Atlantic Ocean from September 2001 to March 2003. Collect Vol Sci Pap ICCAT 55:1679-1718

Morisita M (1959) Measuring of interspecific association and similarity between communities. Mem Fac Sci Kyushu Univ Ser E Biol 3:65-80

Nesis K (1987) Cephalopods of the world: squids, cuttlefishes, octopus and allies. TFH Publications, Neptune City, NJ

Olson RJ, Boggs CH (1986) Apex predation by yellowfin tuna (Thunnus albacares): independent estimates from gastric evacuation and stomach contents, bioenergetics, and cesium concentration. Can J Fish Aquat Sci 43:1760?1775

Palko BJ, Beardsley GL, Richards WJ (1981) Synopsis of the biology of the swordfish, Xiphias gladius Linnaeus. NOAA Tech Rep NMFS 441

Perrin WF, Warner RR, Fiscus CH, Holts DB (1973) Stomach contents of porpoise, Stenella spp., and yellowfin tuna, Thunnus albacares, in mixed-species aggregations. Fish Bull (Wash DC) 71:1077-1092

Pianka ER (1974) Niche overlap and diffuse competition. Proc Natl Acad Sci USA 71:2141-2145

Pianka ER (1978) Evolutionary ecology, 5th edn. Harper \& Collins, New York

Potier M, Marsac F, Lucas V, Sabatié R, Hallier JP, Ménard F (2004) Feeding partitioning among tunas taken in surface and mid-water layers: the case of yellowfin (Thunnus albacares) and bigeye (Thunnus obesus) in the western tropical Indian Ocean. Western Indian Ocean J Mar Sci 3:51-62

Purves WK, Orians GH, Heller HC (1992) Le monde du vivant. Flammarion, Paris
Pusineri C (2005) Niches alimentaires et partage des ressources: les petits cétacés du golfe de Gascogne. PhD dissertation, University of La Rochelle

> Pusineri C, Vasseur Y, Hassani S, Spitz J, Meynier L, Ridoux $\mathrm{V}$ (2005) The food and feeding ecology of the North Atlantic immature albacore tuna, Thunnus alalunga, off the Bay of Biscay. ICES J Mar Sci 62:116-122

Pusineri C, Magnin V, Meynier L, Spitz J, Hassani S, Ridoux $\mathrm{V}$ (2007) Food and feeding ecology of the common dolphin (Delphinus delphis) in the oceanic Northeast Atlantic and comparison with its diet in neritic areas. Mar Mamm Sci 23:30-47

Ridoux V (1994) The diets and dietary segregation of seabirds at the subantarctic Crozet Islands. Mar Ornithol 22:1-192

Ringelstein J, Pusineri C, Hassani S, Meynier L, Nicolas R, Ridoux V (2006) Food and feeding ecology of the striped dolphin, Stenella coeruleoalba, in the oceanic waters of the north-east Atlantic. J Mar Biol Assoc UK 86:909-918

Roe HSJ, Angel MV, Badcock P, Domanski PT, Pugh PR, Thurston $\mathrm{MH}$ (1984) The diel migration and distributions within a mesopelagic community in the North East Atlantic. Prog Oceanogr 13:245-511

Roper CFE, Young RE (1975) Vertical distribution of pelagic cephalopods. Smithson Contrib Zool 209:1-51

Ross ST (1986) Resource partitioning in fish assemblages: a review of field studies. Copeia 1986:352-388

Sekiguchi K, Klages NTW, Best PB (1992) Comparative analysis of the diets of smaller odontocete cetaceans along the coast of southern Africa. S Afr J Mar Sci 12:843-861

Simpson EH (1949) Measurement of diversity. Nature 163:688

Stillwell CE, Kohler NE (1985) Food and feeding ecology of the swordfish in the eastern Atlantic with estimates of daily ration. Mar Ecol Prog Ser 22:239-247

Trillmich F (2002) Sociobiology. In: Perrin WF, Würsig B, Thewissen JGM (eds) Encyclopedia of marine mammals. Academic Press, London, p 1117-1123

Whitehead PJP, Bauchot ML, Hureau JC, Nielsen J, Tortonese E (1989) Fish of the north-eastern Atlantic and the Mediterranean, Vol 1. UNESCO, Paris

Whitehead H, MacLeod CD, Rodhouse P (2003) Differences in niche breadth among some teuthivorous mesopelagic marine mammals. Mar Mamm Sci 19:400-406

Williams TM (2002) Swimming. In: Perrin WF, Würsig B, Thewissen JGM (eds) Encyclopedia of marine mammals. Academic Press, London, p 1213-1221 
Appendix 1. Diet composition by mass and family of prey for each predator. \% $M$ : percentage by mass. For full taxonomic names of predators, see Fig. 1 legend

\begin{tabular}{|c|c|c|c|c|c|}
\hline Prey families & $\begin{array}{l}\text { Blue shark } \\
\mathrm{N}=24 \\
\text { C. Pusineri } \\
\text { (unpubl.) } \\
\% M\end{array}$ & $\begin{array}{c}\text { Swordfish } \\
\mathrm{N}=83 \\
\text { Chancollon et } \\
\text { al. }(2006) \\
\% M\end{array}$ & $\begin{array}{c}\text { Albacore } \\
\mathrm{N}=51 \\
\text { Pusineri et al. } \\
(2005) \\
\% M\end{array}$ & $\begin{array}{c}\text { Common dolphin } \\
\mathrm{N}=61 \\
\text { Pusineri et al. } \\
(2007) \\
\% M\end{array}$ & $\begin{array}{c}\text { Striped dolphin } \\
N=60 \\
\text { Ringlestein et al. } \\
(2006) \\
\% M\end{array}$ \\
\hline Alepocephalidae & & & & & 0.2 \\
\hline Sternoptychidae & & & 22.6 & 1.3 & 0.9 \\
\hline Platytroctidae & & & & 0.3 & 1.5 \\
\hline Chauliodontidae & & & & 0.3 & 4.3 \\
\hline Stomiidae & & & & 0.8 & 1.9 \\
\hline Bathylagidae & & & & 0.2 & 1.9 \\
\hline Myctophidae & & 2.2 & $<0.1$ & 38.7 & 23.0 \\
\hline Paralepididae & & 10.9 & 7.2 & 1.4 & 1.8 \\
\hline Serrivomeridae & & & & & 0.2 \\
\hline Belonidae & & 2.8 & & & \\
\hline Scomberesocidae & & 0.1 & 29.9 & 5.5 & 0.2 \\
\hline Gadidae & & & & $<0.1$ & \\
\hline Trachipteridae & & 5.7 & & & \\
\hline Bramidae & & 14 & & 1.5 & \\
\hline Chiasmodontidae & & & & 0.1 & 0.2 \\
\hline Gempylidae & & & & 0.3 & $<0.1$ \\
\hline Nomeidae & & 0.6 & & 4.3 & 0.2 \\
\hline Other fish & 1.1 & 4.2 & & 0.7 & 2.4 \\
\hline Total fish & 1.1 & 40.5 & 59.7 & 55.4 & 38.7 \\
\hline Vampyroteuthidae & 0.5 & & & & \\
\hline Alloposidae & 34.5 & 1.8 & & & \\
\hline Ocythoidae & 26.5 & 0.8 & & 0.1 & \\
\hline Ancistrocheiridae & 1.2 & & & & \\
\hline Octopoteutidae & & & 2.7 & 0.4 & 0.9 \\
\hline Onychoteuthidae & 1.4 & 1.2 & 0.8 & 3.7 & 5.7 \\
\hline Gonatidae & 7.7 & 8.5 & 35 & 11.7 & 2.4 \\
\hline Pholidoteuthidae & & 0.9 & & 0.2 & 0.2 \\
\hline Histioteuthidae & 14.9 & 1.2 & 0 & 6.7 & 13.3 \\
\hline Brachioteuthidae & & & & 2.1 & 0.2 \\
\hline Ommastrephidae & & 42.4 & & 0.2 & 1.1 \\
\hline Chiroteuthidae & 0.8 & $<0.1$ & & 0.1 & 0.1 \\
\hline Mastigoteuthidae & & $<0.1$ & & & \\
\hline Cranchiidae & 1.8 & 0.1 & 0.3 & 17.9 & 31.9 \\
\hline Sepiolidae & & $<0.1$ & & & $<0.1$ \\
\hline Other cephalopods & 9.2 & 2.3 & & 0.3 & $<0.1$ \\
\hline Total cephalopods & 98.5 & 59.2 & 38.8 & 43.4 & 55.8 \\
\hline Hyperiidae & $<0.1$ & $<0.1$ & 0.2 & $<0.1$ & $<0.1$ \\
\hline Euphausiidae & $<0.1$ & $<0.1$ & 1.3 & $<0.1$ & $<0.1$ \\
\hline Peneidae & & 0.2 & & 0.1 & 0.6 \\
\hline Sergestidae & & & & 0.9 & 2.5 \\
\hline Pasiphaeidae & & & & 0.3 & 1.8 \\
\hline Oplophoridae & & & & 0.1 & 0.2 \\
\hline Other crustaceans & $<0.1$ & & & & 0.1 \\
\hline Total crustaceans & 0.1 & 0.3 & 1.5 & 1.4 & 5.2 \\
\hline Gelatinous & 0.3 & & & & \\
\hline
\end{tabular}

Editorial responsibility: Otto Kinne, Oldendorf/Luhe, Germany
Submitted: July 4, 2006; Accepted: November 1, 2007

Proofs received from author(s): May 12, 2008 